\title{
Granulocyte Colony Stimulating Factor Measurement
}

National Cancer Institute

\section{Source}

National Cancer Institute. Granulocyte Colony Stimulating Factor Measurement. NCI

Thesaurus. Code C82018.

The determination of the amount of granulocyte colony stimulating factor present in a sample. 